\title{
Plant community and soil properties drive arbuscular mycorrhizal fungal diversity: A case study in tropical forests
}

\author{
Jing Zhang ${ }^{1,2}$, Changxin Quan ${ }^{1,3}$, Lingling Ma ${ }^{1,3}$, Guowei Chu ${ }^{1}$, Zhanfeng Liu ${ }^{1,2,4}$, Xuli Tang ${ }^{1,4, *}$ \\ 1 Key Laboratory of Vegetation Restoration and Management of Degraded Ecosystems, South China Botanical Garden, \\ Chinese Academy of Sciences, Guangzhou 510650, China \\ 2 Southern Marine Science and Engineering Guangdong Laboratory (Guangzhou), Guangzhou 511458, China \\ 3 College of Resources and Environment, University of Chinese Academy of Sciences, Beijing 100049, China \\ 4 Center for Plant Ecology, Core Botanical Gardens, Chinese Academy of Sciences, Guangzhou, 510650, China
}

\section{ARTICLE INFO}

Article history:

Received March 20, 2020

Revised May 18, 2020

Accepted June 17, 2020

\section{Keywords:}

Arbuscular mycorrhizal fungi

High-throughput sequencing

Microbes

Plant community traits

Soil properties

Tropical forests

\begin{abstract}
A B S TR A C T
The mutual interdependence of plants and arbuscular mycorrhizal fungi (AMF) is important in carbon and mineral nutrient exchange. However, an understanding of how AMF community assemblies vary in different forests and the underlying factors regulating AMF diversity in native tropical forests is largely unknown. We explored the AMF community assembly and the underlying factors regulating AMF diversity in a young (YF) and an old-growth forest (OF) in a tropical area. The results showed that a total of 53 AMF phylogroups (virtual taxa, VTs) were detected, $38 \pm 1$ in the OF and $34 \pm 1$ in the YF through high-throughput sequencing of 18S rDNA, and AMF community composition was significantly different between the two forests. A structural equation model showed that the forest traits indirectly influenced AMF diversity via the plant community, soil properties and microbes, which explained $44.2 \%$ of the total observed variation in AMF diversity. Plant diversity and biomass were the strongest predictors of AMF diversity, indicating that AMF diversity was dominantly regulated by biotic factors at our study sites. Our study indicated that forest community traits have a predictable effect on the AMF community; plant community traits and soil properties are particularly important for determining AMF diversity in tropical forests.
\end{abstract}

(c) Higher Education Press 2020

\section{Introduction}

Arbuscular mycorrhizal fungi (AMF) are important ecological components of soils, forming symbioses with about $80 \%$ of vascular plants in terrestrial ecosystems (Smith and Read, 2008; Gao et al., 2019). AMF exhibit crucial roles in ecosystem: they are related with plant diversity (Grime et al., 1987; van der Heijden et al., 1998), maintain or increase ecosystem net primary production (van der Heijden et al.,

\footnotetext{
* Corresponding author

E-mail address: xltang@scbg.ac.cn (X. Tang)
}

1998; Vogelsang et al., 2006) and improve soil structure (Wright and Upadhyaya, 1998; Wilson et al., 2009). The extent to which these mentioned above is determined by the AMF community composition (van der Heijden et al., 1998; Lovelock and Ewel, 2005). For example, higher AMF diversity is associated with higher plant diversity, biomass and nutrient uptake (van der Heijden et al., 1998). Specific AMF taxa appear to show different ecological functions. For example, Glomeraceae is expected to confer pathogen protection to plants (Powell et al., 2009), while Gigasporaceae and Scutellosporaceae are of special benefit for phosphorus $(P)$ uptake (Treseder, 2005) and Acaulosporaceae is competitive in low-P soil (Dodd et al., 2000). Knowledge of AMF 
community composition is therefore vital for understanding the functions of AMF in ecosystems.

Estimation of AMF community composition has traditionally been performed by counting identified AMF spores, but molecular methods and high-throughput sequencing technology are now more frequently used (Redecker et al., 2013). Approximately 250 AMF species have been identified worldwide on the basis of spore morphology, while the number of AMF species that may be identified via molecular techniques is expected to exceed 1500 (Börstler et al., 2006; Kivlin et al., 2011), although the number of morphological species is different with molecular techniques. Global sampling showed that the number of AMF phylogroups (virtual taxa, VTs) was 341 (Öpik et al., 2013), and this database is the most commonly used in AMF studies (https://maarjam.botany.ut. ee/). However, most of the studies related to AMF diversity have been conducted in grasslands (Sun et al., 2013; Hiiesalu et al., 2014), farmlands (Bainard et al., 2015; Wang et al., 2015) and pot culture experiments (Joner, 2000; Wang et al., 2008), and less information is available for tropical forests, especially native tropical forests with a rich plant composition (Rodríguez-Echeverría et al., 2017). A recent study found distinct difference in the microbial community composition in forests and pasture, but no significant difference of the microbial community in forests of different ages (FloresRenteria et al., 2020). Sheldrake et al. (2017) identified 72 operational taxonomic units (OTUs) in a long-term litter removal experiment in a tropical forest in Panama, while 147 OTUs were identified in different vegetation types (grasslands, savannas, dry forests and miombo) in a dry tropical area in Africa (Rodríguez-Echeverría et al., 2017). Hence, more information about AMF diversity in tropical regions is needed, especially in native forests.

AMF community composition is thought to be influenced by a series of biotic and/or abiotic factors (Moora, 2014; Chaudhary et al., 2016; Rodríguez-Echeverría et al., 2017). Different vegetation types are believed to harbor different AMF communities (Kivlin et al., 2011) because of diverse host preferences among AMF species (Husband et al., 2002; Gosling et al., 2013). AMF community composition also changes with plant growth and plant community (Chaudhary et al., 2016; Wang et al., 2018) and bacterial dynamics (Pivato et al., 2009; Mahanta et al., 2018). In addition, abiotic factors affect AMF diversity, for example, litter removal (Sheldrake et al., 2017), nitrogen ( $N$ ) and $P$ addition (Jiang et al., 2018; Sheldrake et al., 2018; Zhao et al., 2018) and legacies of land use (Negrete-Yankelevich et al., 2020) because different AMF species have different nutrient acquisition abilities (Cozzolino et al., 2016). Mathematical models have been used to discriminate the most important factors influencing AMF composition. Soil properties such as soil $\mathrm{pH}$, nitrate, organic matter and available phosphorus concentration were proven to relate to the composition of microbial community with different land cover but originated from tropical rain forest (Flores-Renteria et al., 2020). Studies also found the composition of AMF community also related to soil properties, for example, precipitation and soil moisture are the most important determinants of AMF communities (Veresoglou et al., 2013), soil texture was the strongest predictor of the AMF community composition in an ecotone between pastures and agricultural fields (Xiang et al., 2014), and AMF diversity in forest ecosystems is mainly driven by different habitat types with latitude changes (Veresoglou et al., 2019). However, it is unclear whether soil properties have a direct effect on AMF or if they influence plant traits that in turn influence the AMF community composition in tropical forests.

Given the scarcity of AMF data from tropical native ecosystems, two different well-studied native tropical forests were selected to investigate the AMF composition and to analyze how AMF diversity was related to a number of different biotic and abiotic factors. A previous study indicated a larger belowground carbon flux in an old forest (OF, $60 \%$ of the total carbon fixed) than in a young forest (YF, 45\%, Tang et al., 2011). Higher plant diversity and biomass (Peng and Wang, 1983; Tang et al., 2011) and more severe $P$ deficiency have been observed (Huang et al., 2013) in OF than in YF. According to the functional equilibrium model (Johnson, 2010), we hypothesized that AMF diversity would be higher in OF than in YF, since the carbon (C) allocated to AMF can be expected to be proportional to the $C$ allocated belowground (Hawkes et al., 2008), and P deficiency generally leads to higher AMF diversity (Khade et al., 2010). We also attempted to explain AMF diversity variation using the measured abiotic factors, combined with plant traits and microbe-related factors, to ascertain the most important drivers of AMF community assembly. The results will provide novel insight into the AMF community composition and the driving factors of the AMF community in natural tropical forests.

\section{Materials and methods}

\subsection{Site description}

This study was carried out in the Dinghushan Biosphere Reserve (DBR, $23^{\circ} 10^{\prime} \mathrm{N}, 112^{\circ} 32^{\prime} \mathrm{E}$ ) in southern China (Fig. 1). The DBR, covering an area of 1200 ha, was established to protect undisturbed natural monsoon evergreen broad-leaved forests in the 1950s. The DBR has a typical tropical monsoon climate, with mean annual precipitation of $1927 \mathrm{~mm}$, nearly $80 \%$ of which falls in the hot-wet season (April-October), while the remaining $20 \%$ falls in the cool-dry season (OctoberMarch). The annual mean temperature in this area is $22.3^{\circ} \mathrm{C}$. The DBR bedrock is classified as Devonian sandstone and shale (He et al., 1982; Wu et al., 1982). The soil is classified as lateritic red earth (oxisol), with a $\mathrm{pH}$ lower than 4 in the top $10 \mathrm{~cm}$ (Appendix A). More information about this study site can be found in Zhang et al. (2017).

Two forest types, a young forest (YF) and an old-growth forest (OF), were selected for this study. The OF has been well protected from human disturbance for more than 400 years, while the YF is the result of reforestation after a clear cut in the 1950s (Shen et al., 2001). The OF and YF experience the 

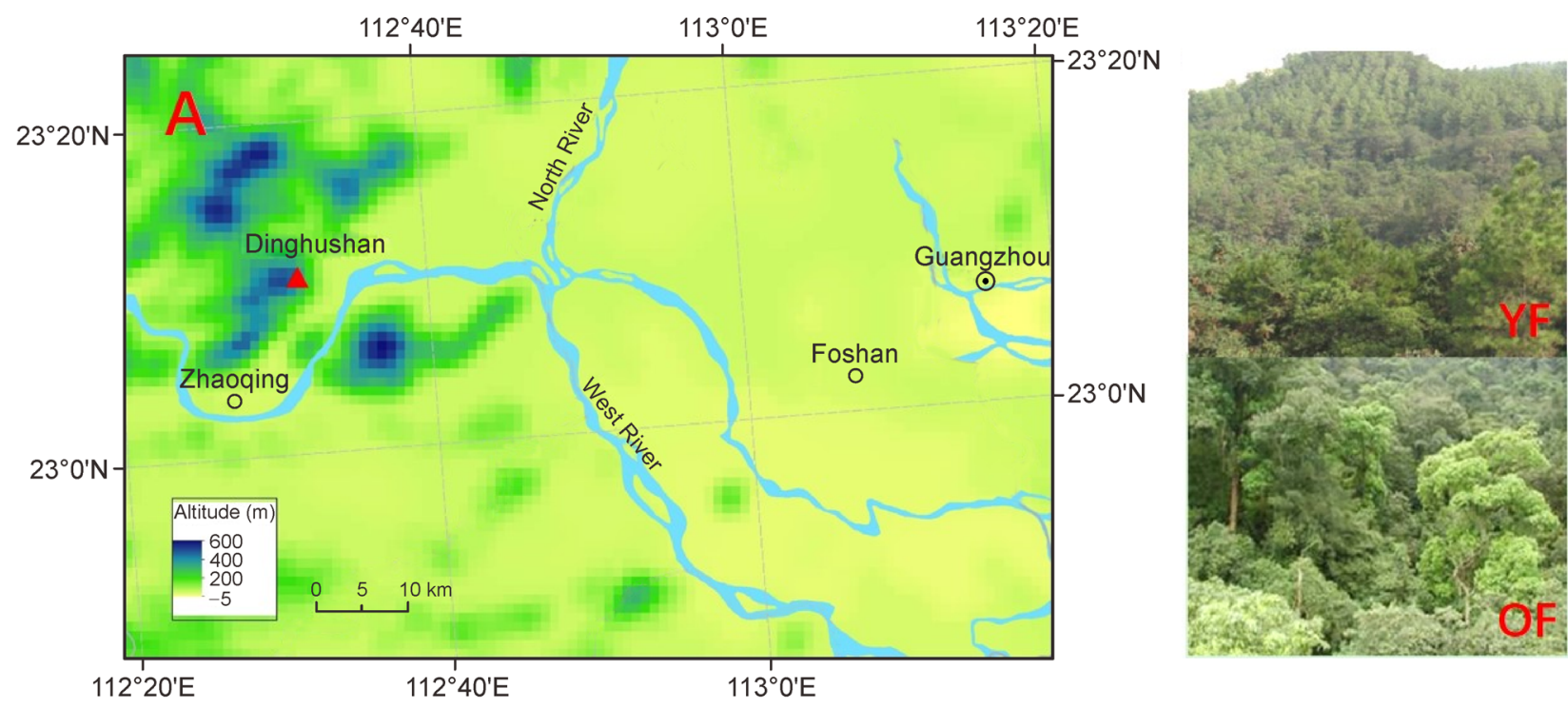

Fig. 1 Location of our study sites (panel A) and pictures of the young (YF) and the old-growth forest (OF).

same climate and environmental changes, as these two sites are only $1 \mathrm{~km}$ apart.

The YF is located in the periphery of the DBR. Pinus massoniana Lamb. was planted at this site in the 1950s. Broad-leaved tree species, including Cratoxylum cochinchinense (Lour.) BI., Mallotus paniculatus (Lam.) Müll. Arg., and Evodia lepta (Spreng.) Merr. then appeared gradually. The YF with dense understory plants is dominated by Dicranopteris pedata (Houtt.) Nakaike. The OF represents zonal vegetation type with a complex community structure. Castanopsis chinensis (Spreng.) Hance, Gironniera subaequalis Planch., Schima superba Gardner et Champ., Syzygium acuminatissimum (Blume) DC. and Syzygium rehderianum Merr. et L. M. Perry. dominate the upper canopy. Aidia canthioides (Champ. ex Benth.) Masam, Psychotria rubra (Lour.) Poir. and Blastus cochinchinensis Lour. dominate the understory, and Cryptocarya concinna Hance, Machilus chinensis (Champ. ex Benth.) Hemsl. and Lophatherum gracile Brongn., dominate the herbaceous layer. Arbuscular mycorrhizae are the major mycorrhizal symbionts in both the YF and the OF with more than $70 \%$ of the plants are AMF hosts in these forests (Zheng et al., 2013).

\subsection{Field sampling}

Twelve $10 \mathrm{~m} \times 10 \mathrm{~m}$ plots were randomly arranged in each forest for soil sampling in July 2015. A composite topsoil (0-10 $\mathrm{cm}$ depth) sample was collected in each plot using a five-spot pattern with a $2.5 \mathrm{~cm}$ diameter auger. Each soil sample was thoroughly mixed and divided into two subsamples. One subsample (approximately $100 \mathrm{~g}$ ) was stored at $-80^{\circ} \mathrm{C}$ in a freezer until DNA extraction, analyses of phospholipid fatty acids (PLFAs) and acid phosphatase activity (APA) (analyzed within 15 days). Another subsample (approximately $300 \mathrm{~g}$ ) was air-dried for the measurement of physicochemical soil properties. Soil properties, including $\mathrm{pH}$, the soil organic carbon (SOC) content, and soil nitrogen (Appendix A), were analyzed with the methods described in Liu et al. (1996). For the measurement of PLFAs and APA, the method of Bossio and Scow (1998) and Schneider et al. (2000) was followed, respectively.

All trees with diameter at breast height $(\mathrm{DBH})>1 \mathrm{~cm}$ or $>1.3 \mathrm{~m}$ in height were investigated in each plot. The species and DBH of each AMF tree (Niu, 1990; Zheng et al., 2013) were recorded in all plots when soil samples were collected. The corresponding biomass of each plot was calculated as described by Wen et al. (1997).

\subsection{Molecular identification of AMF}

Soil DNA was isolated from $0.5 \mathrm{~g}$ of thoroughly mixed soil, employing the Powersoil DNA Isolation kit (Mo Bio Laboratories, Carlsbad, CA, USA). The DNA was then diluted to 10$20 \mathrm{ng} \mathrm{LL}^{-1}$ with double-distilled $\mathrm{H}_{2} \mathrm{O}$ for nested $\mathrm{PCR}$, after the integrity of the DNA was tested. Two pairs of primers were selected to amplify the partial small subunit (SSU) rRNA gene fragment: the universal eukaryotic NS1/NS4 primers (White et al., 1990) and the AMF-specific AMV4.5NF/AMDGR primers (Lumini et al., 2010). The AMV4.5NF/AMDGR primer pair was augmented with Illumina high-throughput sequencing adapters and a $12 \mathrm{bp}$ barcode sequence for multiplexing, leading to the following constructs: AMV4.5NF: AACGCACGCTAGCCCCAAGCTCGTAGTTGAATTTCG; and AMDGR: CCCAACTATCCCTATTAATCAT (the specific primers are indicated in boldface; the barcode is shown in italics; and the connected bases are underlined).

For the first PCR step, each reaction (20 $\mu \mathrm{L}$ volume) contained 0.75 units of Ex Taq DNA polymerase (TaKaRa, Dalian, China), $1 \times$ Ex Taq loading buffer (TaKaR), $0.2 \mathrm{mmol} \mathrm{L}^{-1} \mathrm{dNTP}$ mix, $0.2 \mu \mathrm{mol} \mathrm{L^{-1 }}$ of each primer and 
$50 \mathrm{ng}$ of template DNA (TaKaRa), and the following reaction conditions were applied: $94^{\circ} \mathrm{C}$ for $5 \mathrm{~min}$, followed by 6 cycles at $94^{\circ} \mathrm{C}$ for $45 \mathrm{~s}, 51^{\circ} \mathrm{C}$ for $45 \mathrm{~s}$, and $72^{\circ} \mathrm{C}$ for $1 \mathrm{~min}$, with a final step of $72^{\circ} \mathrm{C}$ for $10 \mathrm{~min}$. The first amplification product was diluted 10 times with $\mathrm{dH}_{2} \mathrm{O}(1: 10)$. For the second PCR step ( $30 \mu \mathrm{L}$ volume), the same conditions were employed as in the first step, except that the amount of template DNA was $1 \mu \mathrm{L}$ in this PCR procedure, and 30 PCR cycles were performed instead of 6 . This procedure was repeated 3 times for each sample during the second round of PCR, and the products were subsequently mixed. All PCR amplifications were performed in a Bio-Rad T100 thermal cycler (Bio-Rad T100, Mississauga, ON, Canada). Subsequently, $2 \mu \mathrm{L}$ of the PCR products was subjected to $1 \%$ agarose gel electrophoresis using DL2000 as the marker and then purified using the EZNATM Gel Extraction Kit (Omega, USA) after excising the bands. Each PCR product was mixed at equimolar concentrations and then subjected to sequencing on an Illumina HiSeq2500 platform.

\subsection{Bioinformatics analysis}

The bioinformatics analysis of the high throughput sequencing data was performed following the methods described by Vasar et al. (2017) and Öpik et al. (2013). Based on analysis of the quality of the Illumina high-throughput sequencing reads, reads showing significant degradation of the 3 '-end sequence, a quality score lower than 20 , adapter contamination or $\mathrm{N}$ exceeding sequences were removed and excluded from further analysis by VSEARCH and USEARCH (v9.0.2132, Edgar et al., 2011) using the QIIME platform (Caporaso et al., 2010). Moreover, the barcode sequence was trimmed to a minimum length of 250 bp by VSEARCH (Caporaso et al., 2010). The data set was checked for chimeric sequences in reference database mode (the MaarjAM database, https:/l maarjam.botany.ut.ee/, Opik et al., 2010), and all potential chimeric sequences were removed before further analysis. The remaining sequences were assigned to virtual taxa (VTs) with the MaarjAM database as the reference database by BLAST v2.5 (Camacho et al., 2009) with the criteria of sequence similarity level $\geqslant 97 \%$ and e-value $<1 e-60$ (Jiang et al., 2018). VTs less than $0.001 \%$ in the database were discarded.

AMF a diversity was represented by the Shannon-Wiener index ( $H^{\prime}$, Eq. (1)). The minimum number of sequencing reads among all samples was 8804; therefore, 8804 effective sequence reads ( $n=1000$ iterations) were randomly extracted from each sample to calculate the a diversity,

$$
H^{\prime}=-\sum\left[p_{\mathrm{i}} \times \ln \left(p_{\mathrm{i}}\right)\right]
$$

$\left(p_{\mathrm{i}}=n_{\mathrm{i}}: N\right.$, where $n_{\mathrm{i}}$ is the number of individuals of $\mathrm{VT} \mathrm{i}$, and $N$ is the total number of individuals across all VTs).

\subsection{Nucleotide sequence accession numbers}

All sequencing data analyzed in this study have been deposited in the NCBI Sequence Read Archive (SRA) under accession numbers SRR6283070- SRR6283093.

\subsection{Statistical analyses}

All data were checked for a normal distribution and homogeneity of variance before statistical analysis, and data with a non-normal distribution were $\log (x+1)$ transformed to ensure a normal distribution. To compare AMF diversity between the YF and OF, we ran an independent samples $t$ test with SPSS 22.0 (SPSS Inc., Chicago, IL, USA).

The relative abundance of AMF VTs in each sample was employed for the AMF community-related analysis. Dissimilarities in species composition of AMF communities between YF and OF were analyzed by nonmetric multidimensional scaling (NMDS), using R package "VEGAN" with the BrayCurtis dissimilarity index ("metaMDS" function, Oksanen et al., 2016). The difference in AMF community composition between the $\mathrm{YF}$ and $\mathrm{OF}$ was analyzed by permutational multivariate analysis of variance (PERMANOVA) using PAST 3.0 software (https://folk.uio.no/ohammer/past/). The corresponding two-dimensional NMDS ordination plots ("enfit" function from R package "VEGAN") was used to correlate AMF community composition with environmental factors.

A structural equation model (SEM) was applied to distinguish the direct and indirect influence of forest traits (YF or OF) on AMF diversity ( $\alpha$ diversity, Shannon-Wiener index). We hypothesized that the vegetation community either directly or indirectly influences AMF diversity through the effects of soil nutrients and microbes (only the significant environmental index $(P<0.05)$ in the NMDS with environmental factor analysis was selected). The plant community index was one synthetic variable of the first principal component (PC1) for AMF tree diversity and biomass, explaining $87.8 \%$ of the total variability. The soil index was another synthetic variable derived from $\mathrm{PC} 1$ for soil moisture, available $\mathrm{N}$, availability of $\mathrm{P}$ (available P/total $\mathrm{P}$ ), soil organic carbon (SOC) and the $\mathrm{pH}$ value, explaining $75.50 \%$ of the variability. The microbe-related index was the PC1 component for APA and total PLFAs, explaining $87.4 \%$ of the total variability. The fitness of the model was evaluated based on the following criteria: $X / \mathrm{df}<2, P>0.05$, root mean square error of approximation $<0.07$ and goodness-of-fit index (GFI) $>0.9$ (Hooper et al., 2008). SEM was conducted using the Amos 17.0 software program (Amos Development Corporation, Crawfordville, FL, USA); the theoretical model is shown in Fig. 5A.

\section{Results}

3.1 AMF diversity and community composition

A total of 966456 SSU rRNA sequences obtained in this study on the basis of a $97 \%$ similarity level were assigned to $53 \mathrm{AMF}$ VTs based on the MaarjAM database (Fig. 2). The number of 

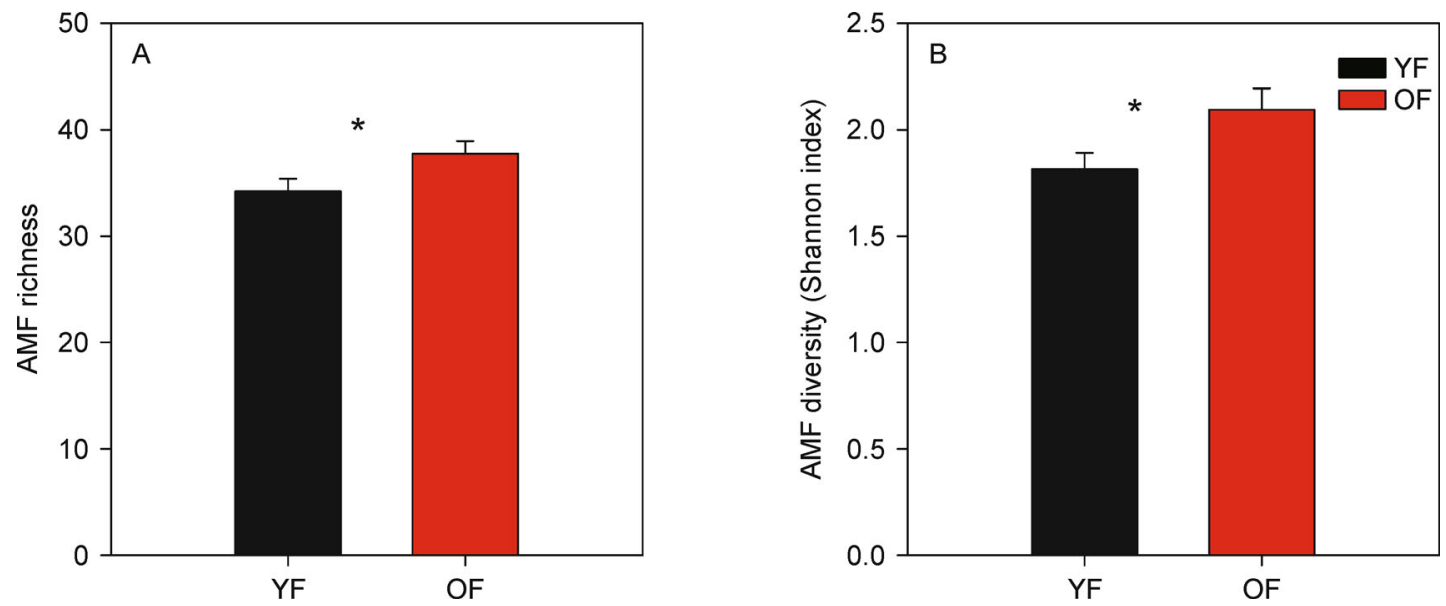

Fig. 2 Arbuscular mycorrhizal fungi (AMF) phylogroups (VTs) number (panel A) and AMF diversity (Shannon index, panel B) in the YF and OF in DBR. Data are shown as mean \pm SD $(n=12)$. YF is young forest, and OF is old-growth forest, * represents significant difference between $Y F$ and OF at $P<0.05$.

AMF VTs identified in the YF $(35 \pm 1)$ was significantly lower than that identified in the OF $(38 \pm 1)(P<0.05$, Fig. $2 A)$. In total, 14 out of 53 AMF VTs were the dominant ( $>1 \%)$ VTs at these study sites, including VT24 (belonging to Acaulosporaceae), VT82 (belonging to Glomeraceae) and VT89 (belonging to Glomeraceae) etc. (Fig. 3). VT348 (belonging to Paraglomeraceae) was the richest species at our study sites accounting for $35.87 \pm 7.89 \%$ of all AMF VTs. Among all the dominant VTs, VT124 (belonging to Glomeraceae), VT126 (belonging to Glomeraceae) and VT369 (belonging to Glomeraceae) differed significantly between the YF and the OF (Fig. 3).

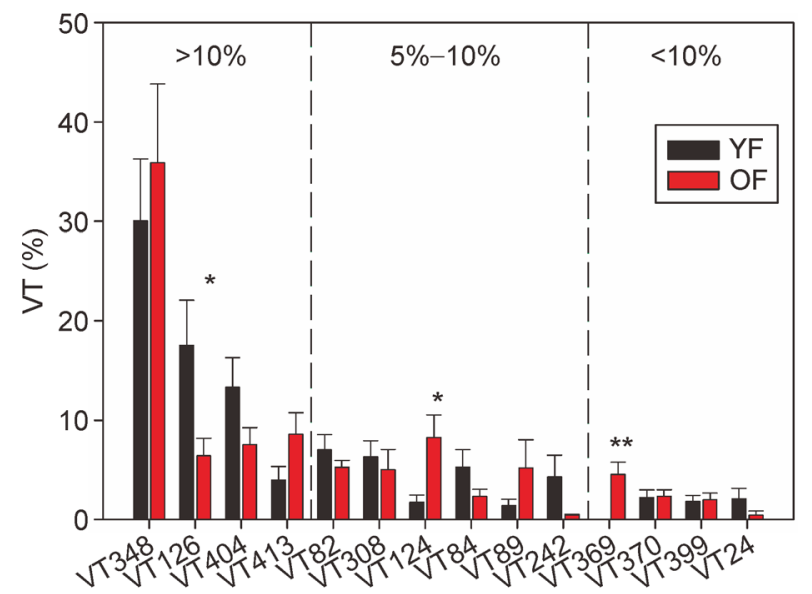

Fig. 3 The relative richness of the dominant arbuscular mycorrhizal fungi phylogroups (VTs) $(>1 \%)$ in the young forest (YF) and the old forest (OF). ${ }^{*}$ and ${ }^{* *}$ indicate that the VT percentage differed significantly at $P<0.05$ and $P<0.01$ respectively between the YF and OF $(n=12)$.

In general, all the obtained VTs were classified as 7 AMF families in our study forests. Glomeraceae and Paraglomeraceae were the dominant AMF families and accounted for more than $95 \%$ of all the AMF (Table 1 ). The relative abundance of Gigasporaceae was significantly higher in the OF $(0.60 \pm 0.25 \%)$ than in the YF $(0.08 \pm 0.03 \%)$, while the relative abundance of Acaulosporaceae, and Ambisporaceae was significantly lower in the OF than in the YF $(P<0.05$, Table 1).

Table 1 Proportions of Arbuscular mycorrhizal fungi (AMF) phylogroups (VTs) classified by family in the YF and OF.

\begin{tabular}{lll}
\hline Family & YF $(\%)$ & OF (\%) \\
\hline Glomeaceae & $55.95 \pm 5.62$ & $57.0 \pm 8.15$ \\
Paraglomeraceae & $37.14 \pm 5.85$ & $41.23 \pm 8.35$ \\
Gigasporaceae & $0.08 \pm 0.03$ & $0.60 \pm 0.25^{*}$ \\
Acaulosporaceae & $2.49 \pm 1.05^{\star}$ & $0.48 \pm 0.41$ \\
Ambisporaceae & $4.29 \pm 1.17^{\star}$ & $0.48 \pm 0.11$ \\
Achaeoporaceae & $0.05 \pm 0.01$ & $0.21 \pm 0.13$ \\
Claroideoglomeraceae & $0.003 \pm 0.001$ & $0.003 \pm 0.001$ \\
\hline
\end{tabular}

a Data are shown as the means \pm SD $(n=12) .{ }^{\mathrm{b}} \mathrm{YF}$, young forest; OF, old forest. ${ }^{c}{ }^{*}$ indicates that the family differed significantly $(P<0.05)$ between the YF and OF, based on an independent sample $t$ test.

The Shannon index calculated by VTs showed that AMF $\alpha$ diversity was significantly higher in the OF $(2.10 \pm 0.10)$ than in the YF $(1.81 \pm 0.08, P<0.05$, Fig. 2B). Non-metric multidimensional scaling (NMDS) based on the relative abundance of VTs also indicated a significant difference in the AMF community between these two forests (Fig. 4). The difference in the AMF community between the YF and OF was also supported by the results of one-way PERMANOVA $(F=2.56$, $P<0.05)$.

3.2 Relationships between AMF diversity and plant community traits, soil properties and microbial-related indexes

The environmental factors fitted onto the NMDS ordinations 
(Fig. 4) showed the explanatory variables (plant community traits, soil properties, and the microbe-related index) to the response variables (AMF community composition) for both the YF and OF. AMF community composition significantly varied with specific plant community traits (tree biomass and diversity), microbe-related indexes (total PLFAs, APA) and soil properties (available $\mathrm{N}$, soil water content, SOC, the ratio of AP/TP and the $\mathrm{pH}$ value) $(P<0.05)$. However, AMF community did not have significant correlations with grass biomass/ diversity, shrub biomass/diversity, total $\mathrm{N}$ or total $\mathrm{P}$ in soil

A structural equation model was employed to assess the extent of the direct or indirect influence of the forest type on AMF diversity (Fig. 5). The fitted models met the significance criteria $\left(X^{2} / \mathrm{df}=1.38, P=0.21\right)$. The plant community traits, soil properties and microbial index explained $44.2 \%$ of the variation in AMF diversity. The forest type mediated AMF diversity indirectly through plant, soil and microbial factors (Fig. 5B). Plant community traits (diversity and biomass) were the strongest driving factors for AMF diversity, with a total path coefficient of 0.66 (Fig. 5B). AMF were also influenced by soil nutrients and microbes, with total path coefficients of 0.24 and 0.05 , respectively, although the influence were not significant $(P>0.05$, Fig. 5B).

\section{Discussion}

4.1 AMF community composition differed between the YF and the OF

The significant difference in AMF diversity and community composition between the young forest (YF) and the oldgrowth forest (OF) $(P<0.05$, Figs. 2, 4) confirmed our first hypothesis, suggesting that the OF harbors higher AMF diversity than the YF. The higher AMF diversity in the OF can probably be explained by the higher plant diversity (Peng and Wang, 1983) and biomass (Tang et al., 2011), more severe P

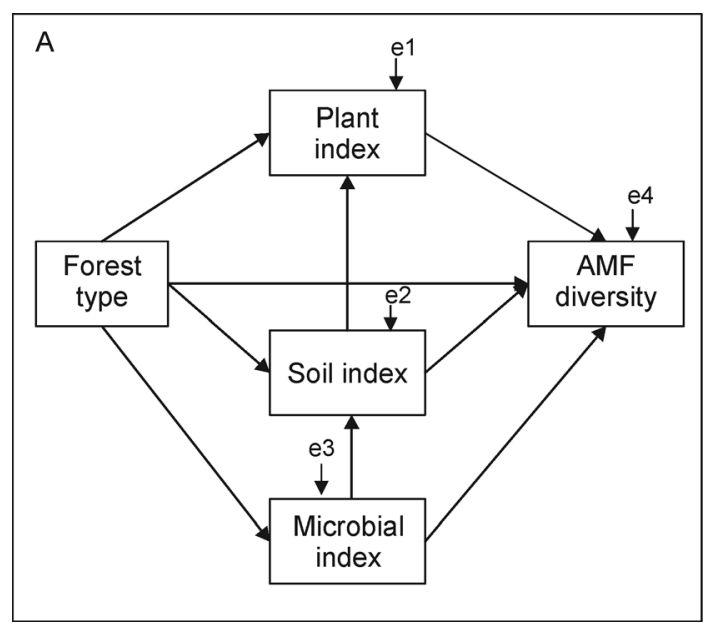

limitation (Huang et al., 2013), and a greater amount of photosynthesis carbon allocated belowground in the OF than in the YF (Tang et al., 2011). Other studies found higher AMF diversity helps plants take up more nutrients (Koide and Kabir,

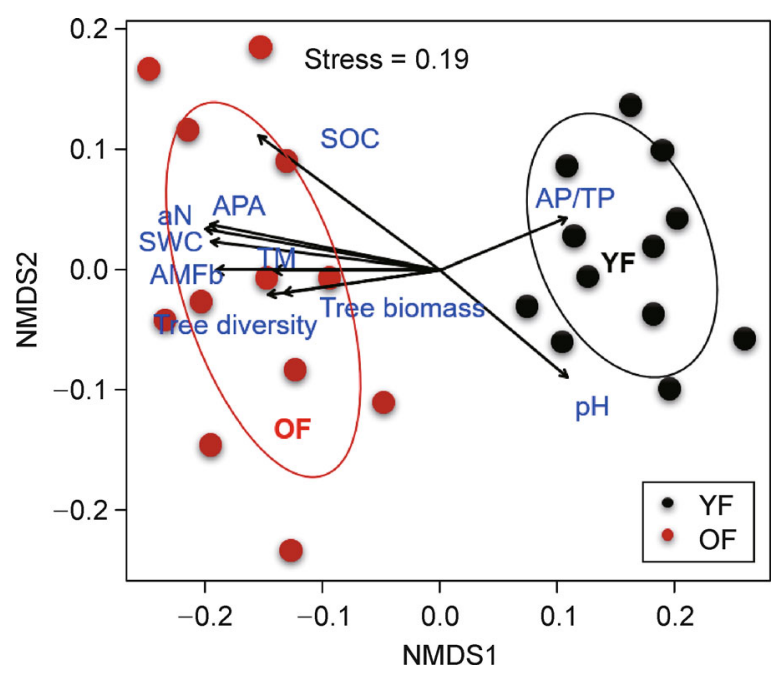

Fig. 4 Non-metric multidimensional scaling (NMDS) of the community composition of arbuscular mycorrhizal fungi in the young forest (red ellipse, YF) and the old forest (dark ellipse, OF) (stress $=0.19$ ). Significant variables $(P<0.05)$ of soil properties (SOC, AP/TP, aN, $\mathrm{pH}$ and $\mathrm{SWC}$ ), plant properties (tree diversity and tree biomass) and microbial properties (TM, AMFb and APA) were fitted onto the NMDS graph according to the results of "envfit" function analysis in R. Tree diversity, AMF tree diversity; tree biomass, biomass of AMF trees; SOC, soil organic carbon; AP/TP, available P/total P; aN, available $\mathrm{N}$; $\mathrm{pH}, \mathrm{pH}$ value; SWC, soil water content; APA, acid phosphatase activity; TM, total biomass of microbes (total PLFAs); AMFb, AMF biomass (16:1 15 ).

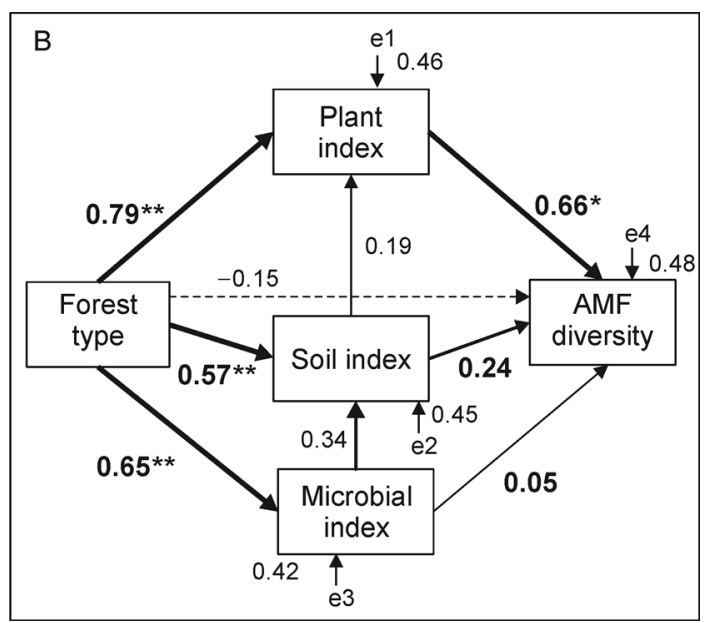

Fig. 5 Structural equation model (panel A, theoretical model; panel B, practical model) showing the hypothesized causal relationships among soil properties, the microbial index, plant-related parameters and AMF diversity (Shannon index). The width of the arrow represents the strength of the standardized path coefficient $\left({ }^{*}, P<0.05 ;{ }^{*}, P<0.01\right)$. The e value indicates residuals. 
2000; Chagnon et al., 2014), therefore, the greater AMF diversity in the OF likely promotes higher plant nutrient uptake and lower interspecific competition, allowing more tree species to coexist. A comparative study revealed higher AMF diversity in macrocosms with a diverse plant composition, alleviating $P$ deficiency to a greater extent than in macrocosms with lower AMF diversity, implying more efficient $\mathrm{P}$ uptake by a more diverse AMF community (van der Heijden et al., 1998). Therefore, plants and AMF may facilitate mutual promotion. Alternatively, the diversity of both partners could be indirectly mediated by environmental factors.

VT348 (classified as Paraglomeraceae) was the richest phylogroup (Fig. 3), and Paraglomeraceae was one of the most dominant AMF families in our study sites (Table 1). Paraglomeraceae could not be identified by traditional sporebased techniques (Morton and Redecker, 2001), and identification was possible only when molecular-based phylogenetic techniques became available because the spores of Paraglomeraceae are very similar to Glomeraceae (Oehl et al., 2003). Paraglomeraceae is a significant component in tilled agricultural soil under organic management, and this family was not related to soil physiochemical characteristics (Gosling et al., 2014). Glomeraceae was the secondary dominant family in our study sites (Table 1), which is consistent with studies conducted in several ecosystems, such as a moso bamboo forest (Qin et al., 2017), grassland ( $\mathrm{Li}$ et al., 2015), and farmland (Hijri et al., 2006). The high abundance of Glomeaceae occurred because this family protects host roots from pathogen infections (Powell et al., 2009) and/or because of the high tolerance of these species to low pH levels (Qin et al., 2017). Unlike Glomeaceae, the percentages of both Gigasporaceae and Acaulosporaceae differed significantly between the OF and the YF (Table 1). The higher proportion of Gigasporaceae found in the OF and the negative correlations with the available $P /$ total $P$ ratio suggest that Gigasporaceae is beneficial for $P$ uptake in tropical forests, especially in the OF (Appendix B and C). Other studies have found that the well-developed hyphae (Powell et al., 2009) and the P transporter operon (Treseder, 2005) of Gigasporaceae enable these fungi to acquire nutrients and alleviate plant $P$ deficiency. Acaulosporaceae was more abundant in the YF than in the OF but showed no significant correlation with any of the examined environmental factors (Appendixes B and C). The high extracellular phosphatase activity observed in Acaulosporaceae (Vosatka and Dodd, 1998) suggests a strong competitive advantage in low-P soils; in this respect, it was unexpected that this family was more common in the YF than in the OF. This might be due to different AMF infection strategies in different forests since $P$ is also deficient in YF. Differences in morphological, physiology or phenological traits among plant taxa that affect the demand or supply of $\mathrm{P}$ lead to variation in plant responses to mycorrhizal infection (Johnson, 2010). Considering the distinct difference in plant composition in these two forests at our study sites (Appendix A), the balance between costs and benefits of mycotrophy may also insert influence on the composition of AMF community. The underlying mechanism by which AMF regulate plant $P$ acquisition deserves intensive study in the future.

4.2 Relationships among AMF diversity and plant community traits, soil properties and microbial-related indexes

The positive correlation between AMF community composition and plant-related indexes (Fig. 4) is explained by the different nutrient demands of different plants (Smith and Read, 2008). van der Heijden et al. (1998) suggested that AMF represent a major factor contributing to plant biomass and diversity because a diverse AMF community increases plant $P$ use efficiency. The significant positive relationship between tree diversity and AMF community composition (Fig. 4) suggests that the higher diversity of one symbiotic partner promotes higher diversity of the other. AMF diversity was significantly correlated with plant biomass in DBR forests (Fig. 4), which is consistent with studies conducted in old-field ecosystems in North America and a tropical low-flooding forest in Mexico, but inconsistent with the results of grass pot culture experiments (van der Heijden et al., 1998; Koch et al., 2012; Solis-Rodriguez et al., 2020). In addition, the OF was proven as N-rich (Lu et al., 2014) and P-limited (Huang et al., 2013; Hou et al., 2015) forest, plants and AMF may form strong mutualism according to Johnson's trade balance model (Johnson, 2010). Previous study on carbon allocation found greater portion of NPP allocated to belowground in the OF than in the YF (Tang et al., 2011), higher plant C supply in the OF also suggested higher AMF demand (Johnson 2010), which may result in higher AMF diversity in the OF compared with the YF.

Soil-related factors (such as soil organic carbon, and available $\mathrm{N}$ ) significantly affected AMF community composition (Fig. 4). The synthetical index of all the above factors was observed to be one of the most important factors influencing AMF diversity, with a total path coefficient of 0.24 (Fig. 5B). However, this path coefficient was offset by the negative effect of the AP/TP ratio on AMF diversity and the positive effect of $\mathrm{pH}$ on AMF diversity. The positive correlation between the AMF community and soil available $\mathrm{N}$ probably resulted from greater plant investment in N-rich extracellular phosphatase (approximately 15\% N) (Treseder and Vitousek, 2001) although $\mathrm{N}$ is rich at our study sites, phosphatase decomposes organic $P$ to enhance available $P$ for uptake by plants (Houlton et al., 2008). Therefore, AMF probably contributes to plant $\mathrm{N}$ uptake due to the large $\mathrm{N}$ requirement associated with this $P$ strategy. AMF can provide a considerable amount of $P$ to plants especially at the growth stage when plants have a higher nutrient requirements in wetlands (Bao et al., 2019). The positive correlation between the AMF community and APA and the availability of P (AP/TP, Fig. 4) at our study sites suggests that AMF contributes to $P$ supply in DBR forests, especially in OF, because AMF hyphae can expand the 
surface area to absorb P, while AMF extraradical hyphae exhibit high extracellular phosphatase activity, to break down organic P (Vosatka and Dodd, 1998; Khade et al., 2010).

The AMF community composition was also influenced by microbial biomass (Fig. 4, Appendix B). Studies suggest that the microbial community can influence the AMF community. For example, Comamonadaceae species act as mycorrhizal helper bacteria and promote infection by Glomus mosseae (Pivato et al., 2009). The significant correlation between AMF diversity and microbial biomass found in our study suggests that AMF interact with the microbial community, although the specific functions of such interactions are unknown (Scheublin et al., 2010). Our results suggested that other microbes probably play a significant role in AMF community assembly, although which specific microbe contributes to AMF diversity was unclear in our study.

\section{Conclusions}

In conclusion, our results showed that different forests exhibited a significantly different AMF community composition. AMF diversity is influenced by plant community traits, soil physicochemical properties and microbe-related factors, which partly explained the observed variance of the AMF community composition. Among all of the evaluated factors, plant community traits (diversity and biomass) were the dominant factors that influenced the AMF community assembly. This study also revealed a possible connection between the different colonization strategies of various AMF families in different forests. For example, Gigasporaceae, a family showing different strategies for alleviating $P$ deficiency, was richer in the OF than in the YF, due to $\mathrm{P}$ deficiency being more severe in the OF than in the YF. This study provides deeper insight into the factors influencing AMF assembly in two natural forests with a rich plant species composition, although a large-scale study is needed in natural tropical forests rich in plant species.

\section{Acknowledgments}

This work was supported by the National Natural Science Foundation of China (31770491, 31270499 and 41430529), Key Special Project for Introduced Talents Team of Southern Marine Science and Engineering Guangdong Laboratory (Guangzhou) (GML2019ZD0408), the Youth Innovation Promotion Association, CAS and Natural Science Foundation of Guangdong Province of China (2019A1515011486). The authors thank Prof. Hakan Wallander (Lund University, Sweden) for writing advice. Mr. Mingzhi Li (Genepioneer Biotechnologies, Nanjing 210014, China) and Dr. Mingsen Qin (Lanzhou University, China) are thanked for providing bioinformatics analysis.

\section{Conflict of interest}

The authors declare that they have no conflict of interest.

\section{Author contributions}

J.Z. and X.T. designed the research, J.Z., C.Q and. G.C. collected the samples, J.Z. and Z.L. performed the experiments and analyzed the data and J.Z., C.Q., L.M. and X.T. wrote the manuscript.

\section{Electronic supplementary material}

Supplementary material is available in the online version of this article at https://doi.org/10.1007/s42832-020-0049-z and is accessible for authorized users.

\section{References}

Bainard, L.D., Dai, M., Gomez, E.F., Torres-Arias, Y., Bainard, J.D., Sheng, M., Eilers, W., Hamel, C., 2015. Arbuscular mycorrhizal fungal communities are influenced by agricultural land use and not soil type among the Chernozem great groups of the Canadian Prairies. Plant and Soil 387, 351-362.

Börstler, B., Renker, C., Kahmen, A., Buscot, F., 2006. Species composition of arbuscular mycorrhizal fungi in two mountain meadows with differing management types and levels of plant biodiversity. Biology and Fertility of Soils 42, 286-298.

Bossio, D., Scow, K., 1998. Impacts of carbon and flooding on soil microbial communities: phospholipid fatty acid profiles and substrate utilization patterns. Microbial Ecology 35, 265-278.

Camacho, C., Coulouris, G., Avagyan, V., Ma, N., Papadopoulos, J., Bealer, K., Madden, T.L., 2009. BLAST plus: architecture and applications. BMC Bioinformatics10, 421.

Caporaso, J.G., Kuczynski, J., Stombaugh, J., Bittinger, K., Bushman, F.D., Costello, E.K., Fierer, N., Pena, A.G., Goodrich, J.K., Gordon, J.I., Huttley, G.A., Kelley, S.T., Knights, D., Koenig, J.E., Ley, R.E., Lozupone, C.A., McDonald, D., Muegge, B.D., Pirrung, M., Reeder, J., Sevinsky, J.R., Tumbaugh, P.J., Walters, W.A., Widmann, J., Yatsunenko, T., Zaneveld, J., Knight, R., 2010. QIIME allows analysis of high-throughput community sequencing data. Nature Methods 7, 335-336.

Chagnon, P., Bradley, R., Klironomos, J., 2014. Plant-fungal symbioses as ecological networks: the need to characterize more than just interaction patterns. Fungal Ecology 12, 10-13.

Chaudhary, V.B., Lau, M., Johnson, N., 2008. Macroecology of microbes biogeography of Glomeromycota. In: Varma, A., ed. Mycorrhiza. Berlin: Springer-Verlag, 529-565.

Cozzolino, V., Di Meo, V., Monda, H., Spaccini, R., Piccolo, A., 2016. The molecular characteristics of compost affect plant growth, arbuscular mycorrhizal fungi, and soil microbial community composition. Biology and Fertility of Soils 52, 15-29.

Dodd, J.C., Boddington, C.L., Rodriguez, A., Gonzalez-Chavez, C., Mansur, I., 2000. Mycelium of arbuscular mycorrhizal fungi (AMF) from different genera: form, function and detection. Plant and Soil 226, 131-151.

Edgar, R.C., Haas, B.J., Clemente, J.C., Quince, C., Knight, R., 2011. UCHIME improves sensitivity and speed of chimera detection. 
Bioinformatics (Oxford, England) 27, 2194-2200.

Flores-Renteria, D., Sanchez-Gallen, I., Morales-Rojas, D., Larsen, J., Alvarez-Sanchez, J., 2020. Changes in the abundance and composition of a microbial community associated with land use change in a mexican tropical rain forest. Journal of Soil Science and Plant Nutrition. 1-12.

Gao, C., Montoya, L., Xu, L., Madera, M., Hollingsworth, J., Purdom, E., Hutmacher, R.B., Dahlberg, J.A., Coleman-Derr, D., Lemaux, P. G., Taylor, J.W., 2019. Strong succession in arbuscular mycorrhizal fungal communities. ISME Journal 13, 214-226.

Gosling, P., Mead, A., Proctor, M., Hammond, J.P., Bending, G.D., 2013. Contrasting arbuscular mycorrhizal communities colonizing different host plants show a similar response to a soil phosphorus concentration gradient. New Phytologist 198, 546-556.

Gosling, P., Proctor, M., Jones, J., Bending, G.D., 2014. Distribution and diversity of Paraglomus spp. in tilled agricultural soils. Mycorrhiza 24, 1-11.

Grime, J., Mackey, J., Hillier, S., Read, D., 1987. Floristic diversity in a model system using experimental microcosms. Nature 328, 420 422.

Hawkes, C.V., Hartley, I.P., Ineson, P., Fitter, A.H., 2008. Soil temperature affects carbon allocation within arbuscular mycorrhizal networks and carbon transport from plant to fungus. Global Change Biology 14, 1181-1190.

$\mathrm{He}, \mathrm{C}$., Chen, S., Liang, Y., 1982. The soils of Dinghushan biosphere reserve. Tropical and subtropical forest ecosystem 1, 25-38.

Hiiesalu, I., Pärtel, M., Davison, J., Gerhold, P., Metsis, M., Moora, M., Öpik, M., Vasar, M., Zobel, M., Wilson, S.D., 2014. Species richness of arbuscular mycorrhizal fungi: associations with grassland plant richness and biomass. New Phytologist 203, 233-244.

Hijri, I., Sýkorová, Z., Oehl, F., Ineichen, K., Mäder, P., Wiemken, A., Redecker, D., 2006. Communities of arbuscular mycorrhizal fungi in arable soils are not necessarily low in diversity. Molecular Ecology 15, 2277-2289.

Hooper, D., Coughlan, J., Mullen, M., 2008. Structural equation modelling: Guidelines for determining model fit. Electronic Journal of Business Research Methods 6, 53-60.

Hou, E., Chen, C., Wen, D., Liu, X., 2015. Phosphatase activity in relation to key litter and soil properties in mature subtropical forests in China. Science of the Total Environment 515, 83-91.

Houlton, B.Z., Wang, Y.P., Vitousek, P.M., Field, C.B., 2008. A unifying framework for dinitrogen fixation in the terrestrial biosphere. Nature 454, 327-330.

Huang, W., Liu, J., Wang, Y.P., Zhou, G., Han, T., Li, Y., 2013. Increasing phosphorus limitation along three successional forests in southern China. Plant and Soil 364, 181-191.

Husband, R., Herre, E., Turner, S., Gallery, R., Young, J., 2002. Molecular diversity of arbuscular mycorrhizal fungi and patterns of host association over time and space in a tropical forest. Molecular Ecology 11, 2669-2678.

Jiang, S., Liu, Y., Luo, J., Qin, M., Johnson, N.C., Opik, M., Vasar, M., Chai, Y., Zhou, X., Mao, L., Du, G., An, L., Feng, H., 2018. Dynamics of arbuscular mycorrhizal fungal community structure and functioning along a nitrogen enrichment gradient in an alpine meadow ecosystem. New Phytologist 220, 1222-1235.

Johnson, N.C., 2010. Resource stoichiometry elucidates the structure and function of arbuscular mycorrhizas across scales. New Phytologist 185, 631-647.

Joner, E., 2000. The effect of long-term fertilization with organic or inorganic fertilizers on mycorrhiza-mediated phosphorus uptake in subterranean clover. Biology and Fertility of Soils 32, 435-440.

Khade, S.W., Rodrigues, B.F., Sharma, P.K., 2010. Arbuscular mycorrhizal status and root phosphatase activities in vegetative Carica papaya L. varieties. Acta Physiologiae Plantarum 32, 565 574.

Kivlin, S.N., Hawkes, C.V., Treseder, K.K., 2011. Global diversity and distribution of arbuscular mycorrhizal fungi. Soil Biology \& Biochemistry 43, 2294-2303.

Koch, A.M., Antunes, P.M., Klironomos, J.N., 2012. Diversity effects on productivity are stronger within than between trophic groups in the arbuscular mycorrhizal symbiosis. PLoS One 7, e36950.

Koide, R.T., Kabir, Z., 2000. Extraradical hyphae of the mycorrhizal fungus Glomus intraradices can hydrolyse organic phosphate. New Phytologist 148, 511-517.

Li, X., Zhang, J., Gai, J., Cai, X., Christie, P., Li, X., 2015. Contribution of arbuscular mycorrhizal fungi of sedges to soil aggregation along an altitudinal alpine grassland gradient on the Tibetan Plateau. Environmental Microbiology 17, 2841-2857.

Liu, G., Jiang, N., Zhang, L., Liu, Z., 1996. Soil physical and chemical analysis and description of soil profiles. Beijing: China Standard Methods Press.

Lovelock, C.E., Ewel, J.J., 2005. Links between tree species, symbiotic fungal diversity and ecosystem functioning in simplified tropical ecosystems. New Phytologist 167, 219-228.

Lu, X., Mao, Q., Gilliam, F.S., Luo, Y., Mo, J., 2014. Nitrogen deposition contributes to soil acidification in tropical ecosystems. Global Change Biology 20, 3790-3801.

Lumini, E., Orgiazzi, A., Borriello, R., Bonfante, P., Bianciotto, V., 2010. Disclosing arbuscular mycorrhizal fungal biodiversity in soil through a land-use gradient using a pyrosequencing approach. Environmental Microbiology 12, 2165-2179.

Mahanta, D., Rai, R., Dhar, S., Varghese, E., Raja, A., Purakayastha, T., 2018. Modification of root properties with phosphate solubilizing bacteria and arbuscular mycorrhiza to reduce rock phosphate application in soybean-wheat cropping system. Ecological Engineering 111, 31-43.

Moora, M., 2014. Mycorrhizal traits and plant communities: perspectives for integration. Journal of Vegetation Science 25, 1126-1132.

Morton, J.B., Redecker, D., 2001. Two new families of Glomales, Archaeosporaceae and Paraglomaceae, with two new genera Archaeospora and Paraglomus, based on concordant molecular and morphological characters. Mycologia 93, 181-195.

Negrete-Yankelevich, S., Cultidmedina, C.A., Fuentespangtay, T., Alvarezsanchez, J., Cram, S., Garciaperez, J.A., Fragoso, C., Martinezromero, E., Rojas, P., Varelafregoso, L., Bueno-Villegas, J., Barois, I., 2020. Disentangling the effects of legacies from those of current land use on soil properties in Los Tuxtlas Biosphere Reserve, Mexico. Applied Soil Ecology 153, 103578.

Niu, J., 1990. An investigation on mycorrhiza from Dinghu Shan. Tropical and Subtropical Forest Ecosystem Research 6, 37-40.

Oehl, F., Sieverding, E., Ineichen, K., Mader, P., Boller, T., Wiemken, A., 2003. Impact of land use intensity on the species diversity of 
arbuscular mycorrhizal fungi in agroecosystems of Central Europe. Applied and Environmental Microbiology 69, 2816-2824.

Opik, M., Vanatoa, A., Vanatoa, E., Moora, M., Davison, J., Kalwij, J. M., Reier, U., Zobel, M., 2010. The online database MaarjAM reveals global and ecosystemic distribution patterns in arbuscular mycorrhizal fungi (Glomeromycota). New Phytologist 188, 223 241.

Öpik, M., Zobel, M., Cantero, J.J., Davison, J., Facelli, J.M., Hiiesalu, I., Jairus, T., Kalwij, J.M., Koorem, K., Leal, M.E., Liira, J., Metsis, M., Neshataeva, V., Paal, J., Phosri, C., Põlme, S., Reier, Ü., Saks, Ü., Schimann, H., Thiéry, O., Vasar, M., Moora, M., 2013. Global sampling of plant roots expands the described molecular diversity of arbuscular mycorrhizal fungi. Mycorrhiza 23, 411-430.

Peng, S., Wang, B., 1983. Analysis on the forest communities of Dinghushan: I. Species diversity. Ecologic Science 1, 11-17.

Pivato, B., Offre, P., Marchelli, S., Barbonaglia, B., Mougel, C., Lemanceau, P., Berta, G., 2009. Bacterial effects on arbuscular mycorrhizal fungi and mycorrhiza development as influenced by the bacteria, fungi, and host plant. Mycorrhiza 19, 81-90.

Powell, J.R., Parrent, J.L., Hart, M.M., Klironomos, J.N., Rillig, M.C., Maherali, H., 2009. Phylogenetic trait conservatism and the evolution of functional trade-offs in arbuscular mycorrhizal fungi. Proceedings of the Royal Society of London. Series B, Biological Sciences 276, 4237-4245.

Qin, H., Chen, J., Wu, Q., Niu, L., Li, Y., Liang, C., Shen, Y., Xu, Q., 2017. Intensive management decreases soil aggregation and changes the abundance and community compositions of arbuscular mycorrhizal fungi in Moso bamboo (Phyllostachys pubescens) forests. Forest Ecology and Management 400, 246-255.

Redecker, D., Schüßler, A., Stockinger, H., Stürmer, S.L., Morton, J. B., Walker, C., 2013. An evidence-based consensus for the classification of arbuscular mycorrhizal fungi (Glomeromycota). Mycorrhiza 23, 515-531.

Rodríguez-Echeverría, S., Teixeira, H., Correia, M., Timóteo, S., Heleno, R., Öpik, M., Moora, M., 2017. Arbuscular mycorrhizal fungi communities from tropical Africa reveal strong ecological structure. New Phytologist 213, 380-390.

Scheublin, T.R., Sanders, I.R., Keel, C., Van Der Meer, J.R., 2010. Characterisation of microbial communities colonising the hyphal surfaces of arbuscular mycorrhizal fungi. ISME Journal 4, 752763.

Schneider, K., Turrión, M.B., Gallardo, J.F., 2000. Modified method for measuring acid phosphatase activities in forest soils with high organic matter content. Communications in Soil Science and Plant Analysis 31, 3077-3088.

Sheldrake, M., Rosenstock, N.P., Mangan, S., Revillini, D., Sayer, E. J., Olsson, P.A., Verbruggen, E., Tanner, E.V.J., Turner, B.L., Wright, S.J., 2018. Responses of arbuscular mycorrhizal fungi to long-term inorganic and organic nutrient addition in a lowland tropical forest. ISME Journal 12, 2433-2445.

Sheldrake, M., Rosenstock, N.P., Revillini, D., Olsson, P.A., Mangan, S., Sayer, E.J., Wallander, H., Turner, B.L., Tanner, E.V., 2017. Arbuscular mycorrhizal fungal community composition is altered by long-term litter removal but not litter addition in a lowland tropical forest. New Phytologist 214, 455-467.

Shen, C., Yi, W., Sun, Y., Xing, C., Yang, Y., Yuan, C., Li, Z., Peng, S.,
An, Z., Liu, T., 2001. Distribution of ${ }^{14} \mathrm{C}$ and ${ }^{13} \mathrm{C}$ in forest soils of the Dinghushan Biosphere Reserve. Radiocarbon 43, 671-678.

Smith, S.E., Read, D.J., 2008. Mycorrhizal symbiosis. Cambridge: Academic Press.

Solis-Rodriguez, U.R.J., Ramos-Zapata, J.A., Hernandez-Cuevas, L., Salinas-Peba, L., Guadarrama, P., 2020. Arbuscular mycorrhizal fungi diversity and distribution in tropical low flooding forest in Mexico. Mycological Progress 19, 195-204.

Sun, X., Su, Y., Zhang, Y., Wu, M., Zhang, Z., Pei, K., Sun, L., Wan, S., Liang, Y., 2013. Diversity of arbuscular mycorrhizal fungal spore communities and its relations to plants under increased temperature and precipitation in a natural grassland. Chinese Science Bulletin 58, 4109-4119.

Tang, X., Wang, Y.P., Zhou, G., Zhang, D., Liu, S., Liu, S., Zhang, Q., Liu, J., Yan, J., 2011. Different patterns of ecosystem carbon accumulation between a young and an old-growth subtropical forest in Southern China. Plant Ecology 212, 1385-1395.

Treseder, K.K., 2005. Nutrient Acquisition Strategies of Fungi and Their Relation to Elevated Atmospheric $\mathrm{CO}_{2}$, The Fungal Community: Its Organization and Role in the Ecosystem, pp. 713-731.

Treseder, K.K., Vitousek, P.M., 2001. Effects of soil nutrient availability on investment in acquisition of $\mathrm{N}$ and $\mathrm{P}$ in Hawaiian rain forests. Ecology 82, 946-954.

van der Heijden, M.G., Klironomos, J.N., Ursic, M., Moutoglis, P., Streitwolf-Engel, R., Boller, T., Wiemken, A., Sanders, I.R., 1998. Mycorrhizal fungal diversity determines plant biodiversity, ecosystem variability and productivity. Nature 396, 69-72.

Vasar, M., Andreson, R., Davison, J., Jairus, T., Moora, M., Remm, M., Young, J., Zobel, M., Öpik, M., 2017. Increased sequencing depth does not increase captured diversity of arbuscular mycorrhizal fungi. Mycorrhiza 27, 761-773.

Veresoglou, S.D., Caruso, T., Rillig, M.C., 2013. Modelling the environmental and soil factors that shape the niches of two common arbuscular mycorrhizal fungal families. Plant and Soil 368, 507-518.

Veresoglou, S.D., Liu, L., Xu, T.L., Rillig, M.C., Wang, M.E., Wang, J. T., Chen, Y.L., Hu, Y.J., Hao, Z.P., Chen, B.D., 2019. Biogeographical constraints in Glomeromycotinan distribution across forest habitats in China. Journal of Ecology 107, 684-695.

Vogelsang, K.M., Reynolds, H.L., Bever, J.D., 2006. Mycorrhizal fungal identity and richness determine the diversity and productivity of a tallgrass prairie system. New Phytologist 172, 554-562.

Vosatka, M., Dodd, J.C., 1998. The role of different arbuscular mycorrhizal fungi in the growth of Calamagrostis villosa and Deschampsia flexuosa, in experiments with simulated acid rain. Plant and Soil 200, 251-263.

Wang, K., He, X., Xie, L., Zhao, L., 2018. Arbuscular mycorrhizal fungal community structure and diversity are affected by host plant species and soil depth in the Mu Us Desert, northwest China. Arid Land Research and Management 32, 198-211.

Wang, Y., Li, T., Li, Y., Bjoern, L.O., Rosendahl, S., Olsson, P.A., Li, S., $\mathrm{Fu}, \mathrm{X} ., 2015$. Community dynamics of arbuscular mycorrhizal fungi in high-input and intensively irrigated rice cultivation systems. Applied and Environmental Microbiology 81, 2958-2965.

Wang, Y.Y., Vestberg, M., Walker, C., Hurme, T., Zhang, X., Lindström, K., 2008. Diversity and infectivity of arbuscular mycorrhizal fungi in 
agricultural soils of the Sichuan Province of Chinese mainland. Mycorrhiza 18, 59-68.

Wen, D., Wei, P., Kong, G., Zhang, Q., Huang, Z., 1997. Biomass study of the community of Castanopsis chinessis + Cryptocarya concinna + Schima superby in a southern China reserve. Acta Ecologica Sinica 17, 497-504.

White, T.J., Bruns, T., Lee, S., Taylor, J., 1990. Amplification and direct sequencing of fungal ribosomal RNA genes for phylogenetics, PCR protocols: a guide to methods and applications. Academic Press, pp. 315-322.

Wilson, G.W., Rice, C.W., Rillig, M.C., Springer, A., Hartnett, D.C., 2009. Soil aggregation and carbon sequestration are tightly correlated with the abundance of arbuscular mycorrhizal fungi: results from long-term field experiments. Ecology Letters 12, 452461.

Wright, S., Upadhyaya, A., 1998. A survey of soils for aggregate stability and glomalin, a glycoprotein produced by hyphae of arbuscular mycorrhizal fungi. Plant and Soil 198, 97-107.

Wu, H., Deng, H., Zheng, L., Liu, Y., 1982. Physico-geographical features of Dinghushan and their dynamic analyses. Tropical and Subtropical Forest Ecosystem Research 1, 1-10.

Xiang, D., Verbruggen, E., Hu, Y., Veresoglou, S.D., Rillig, M.C., Zhou, W., Xu, T., Li, H., Hao, Z., Chen, Y., Chen, B., 2014. Land use influences arbuscular mycorrhizal fungal communities in the farming-pastoral ecotone of northern China. New Phytologist 204, 968-978.

Zhang, J., Tang, X., Zhong, S., Yin, G., Gao, Y., He, X., 2017. Recalcitrant carbon components in glomalin-related soil protein facilitate soil organic carbon preservation in tropical forests. Scientific Reports 7, 2391.

Zhao, A., Liu, L., Xu, T., Shi, L., Xie, W., Zhang, W., Fu, S., Feng, H., Chen, B., 2018. Influences of canopy nitrogen and water addition on AM fungal biodiversity and community composition in a mixed deciduous forest of China. Frontiers of Plant Science 9, 9.

Zheng, K., Tang, X., Zhang, J., Han, T., 2013. Mycorrhizae respond to plant diversity in monsoon evergreen broadleaved forest succession choronsequence. Ecology and Environmental Sciences 22, 729-738. 